\title{
The preoperative serum CA125 can predict the lymph node metastasis in endometrioid-type endometrial cancer
}

\author{
Mehmet Ünsal' ${ }^{1}$, Gunsu Kimyon Comert ${ }^{2}$, Alper Karalok², Derman Basaran², Osman Turkmen², \\ Gokhan Boyraz², Tolga Tasci², Sevgi Koc², Nurettin Boran², Gokhan Tulunay², Taner Turan² \\ ${ }^{1}$ Etlik Zubeyde Hanim Women's Health Training and Research Hospital, Faculty of Medicine, University of Health Sciences, De- \\ partment of Gynecology, Ankara, Turkey \\ 2Etlik Zubeyde Hanim Women's Health Training and Research Hospital, Faculty of Medicine, University of Health Sciences, De- \\ partment of Gynecologic Oncology, Kecioren, Ankara, Turkey
}

\begin{abstract}
Objectives: To evaluate the predictive value of preoperative CA125 in extra-uterine disease and its association with poor prognostic factors in endometrioid-type endometrial cancer (EC).

Material and methods: A total of 423 patients with pathologically proven endometrioid-type EC were included in the study. The association between preoperative CA 125 level and surgical-pathological factors was evaluated. The conventional cut-off value was defined as $35 \mathrm{IU} / \mathrm{mL}$.

Results: A high CA125 level ( $>35 \mathrm{IU} / \mathrm{mL}$ ) was significantly associated with all of the studied poor prognostic factors, except grade. The risk of lymph node metastasis (LNM) increased from $15.9 \%$ to $45.7 \%$ when CA125 level was $>35 \mathrm{IU} / \mathrm{mL}$ $(p<0.05)$. The optimal cut-off value for the prediction of LNM in patients aged $>50$ years was determined to be $16 \mathrm{IU} / \mathrm{mL}$ (sensitivity, specificity, positive predictive value, and negative predictive value were $71 \%, 60 \%, 35 \%$, and $87 \%$, respectively.) Conclusions: Preoperative CA125 level was significantly related with the extent of the disease and LNM. The age-dependent cut-off level of CA125 can improve the prediction of LNM in endometrioid-type EC. For older patients, CA125 level of $>16 \mathrm{IU} / \mathrm{ml}$ could be used to predict LNM. However, further studies are needed to evaluate the appropriate cut-off level of CA125 for younger patients.
\end{abstract}

Key words: preoperative CA125; endometrial cancer; lymph node metastases; poor prognostic factors

Ginekologia Polska 2018; 89, 11:599-606

\section{INTRODUCTION}

Endometrial cancer (EC) is the most common gynecological malignancy in women [1]. Eighty-five percent of EC is of the endometrioid-type [2]. Even though the Cancer Committee of International Federation of Obstetricians and Gynecologists (FIGO) continues to recommend extended surgical staging in EC, necessity of routine lymphadenectomy still remains controversial [3]. It may be possible to provide information regarding the risk of lymph node metastases (LNM) or necessity of extended surgical staging of patients before surgery, which may be helpful in informed decision.

Assessment of preoperative CA125 has been found to be clinically useful in EC. A high level of CA125 has been associated with deep myometrial invasion, extra-uterine spread, LNM, and advanced stage of EC [4, 5]. Furthermore, different cut-off values of CA125 with regard to each of the poor prognostic factor were identified [6-8]. In some studies, it was revealed that the cut-off values of CA125 for LNM prediction changes according to age groups $[4,9]$. However, the cut-off values of CA125 that predict the spread of disease, LNM, or necessity of lymphadenectomy still remains controversial.

\section{Objectives}

The main purpose of this study is to evaluate the role of preoperative CA125 levels and to determine the age-strat- 
ified cut-off levels for predicting the extent of the disease and LNM in endometrioid-type EC patients.

\section{MATERIAL AND METHODS}

The data of 534 patients with epithelial EC who underwent at least a total abdominal hysterectomy and bilateral salpingo-oophorectomy between January 1993 and May 2013 in our clinic and whose CA125 level was known were reviewed. Data were obtained from the electronic database of a gynecological oncology clinic as well as patient files. Among the 534 patients, 26 patients with secondary primary malignancy and 85 patients with non-endometrioid-type EC were excluded. Finally, the study included 423 patients who had endometrioid-type EC. Institutional review board approval was obtained before the study $(2016 ; 204 / 16)$.

In our clinic, a frozen section (FS) is routinely utilized for patients with EC and staging surgery is performed for the patients whose FS analysis revealed non-endometrioid adenocarcinoma, FIGO grade 2 or 3 disease, myometrial invasion depth of $\geq 1 / 2$, cervical involvement, and tumor size of $>2 \mathrm{~cm}$. Furthermore, patients with a preoperative diagnosis of FIGO grade 3 disease or high-risk cell type undergo staging surgery directly. Staging surgery typically involves total abdominal hysterectomy, bilateral salpingo-oophorectomy, systematic pelvic-paraaortic lymphadenectomy, omentectomy, and cytologic sampling. Lymphadenectomy was performed in most of the patients by skeletonizing both pelvic and paraaortic regions. Nevertheless, some patients were treated by sampling the suspicious lymph nodes as per the surgeon's discretion, especially based on patient characteristics such as high risk of comorbidity and morbid obesity. Because patients with positive lymph nodes were evaluated, patients who had undergone lymph node sampling were also included in the study. Bilateral pelvic lymphadenectomy was performed to complete skeletonization, in which case, all lymphatic tissues were present around the common, external, and internal iliac vessels as well as in the obturator fossa that was removed after visualization of the obturator nerve. The superior surgical dissection margin for pelvic nodes was the aortic bifurcation, and the anterior distal surgical dissection margin was the circumflex iliac vein. The presacral lymphatic tissue was harvested separately. The upper limit of paraaortic lymphadenectomy was renal veins. In case of intraoperative identification of a macroscopic disease, cytoreductive surgical techniques are used in addition to staging surgery. Patients were staged according to FIGO 2009 surgical staging criteria of EC [10]. Tumor size was described as the largest diameter of the tumor present in the uterus.

Blood samples were taken from the patients just before surgery for analyzing CA 125 levels. CA125 levels were measured using enzyme immune-radiometric assay with monoclonal antibody (ELSA-CA $125 \mathrm{Il}$; CIS Bio International, Filiale de Schering S.A., France), and the conventional cut-off value was defined as $35 \mathrm{IU} / \mathrm{mL}$ ( $\leq 35 \mathrm{IU} / \mathrm{mL}$ vs. $>35 \mathrm{IU} / \mathrm{mL}$ ).

Patients that had complete clinical response to initial treatment were followed-up every 3 months for the first 2 years, semi-annually for the next 3 years, and annually thereafter. Pelvic examination, abdomino-pelvic ultrasonography, complete blood count, and blood chemistry were performed at every follow-up visit. Follow-up chest X-ray was performed yearly, but in cases of clinical suspicion it was used as needed. Thoracic and/or abdominal computerized tomography was also performed as needed. CA125 level was tested during the follow-up, even though it is not checked on a routine basis. Time from initial surgery to death or the last contact was defined as median follow-up time. Disease-free survival (DFS) was defined as the time period from initial surgery to recurrence of disease.

In the univariate analysis, the association between preoperative level of CA125 and surgical-pathological factors were evaluated by using chi-square test for categorical variables and by using ANOVA test for continuous variables. To define age-dependent CA125 cut-off values for predicting surgical and pathological factors, the patients in the study group were divided into two age-based groups ( $\leq 50$ vs. $>50$ years). This cut-off age was considered because of the mean menopausal age in our population [11]. Receiver operating characteristic (ROC) curve was used to define the age-related optimal preoperative CA125 level for LNM prediction. Disease-free survival analysis on categorical variables was performed using the Kaplan-Meier method, and significant differences between groups were identified using the log-rank test. The factors having a $p$ value $<0.25$ in the univariate analysis were included in the multivariate analysis. The multivariate analysis model was created using the variables, which were not inter-related, and this analysis was performed using the Cox proportional hazards model. Statistical Package for Social Sciences (SPSS; SPSS Inc., Chicago IL, USA), version 17.0, software was used for statistical analysis. The cut-off for statistical significance was set at a $p$ value of $<0.05$.

\section{RESULTS}

The median age of the study group was 56.7 years (range: 29-83). The median tumor size was $42.6 \mathrm{~mm}$ (range; 10-130 mm). Detailed surgical and pathological findings are shown in Table 1. Lymphadenectomy was performed on 246 patients and the median number of removed lymph nodes was 45 (range; 5-122).

The mean preoperative CA125 level was $40.3 \mathrm{IU} / \mathrm{mL}$ in the entire cohort. CA125 level was significantly higher in patients who had advanced stage of disease, high-grade tumor, deep myometrial invasion, uterine serosal involvement, 


\section{Table 1. Patients' surgical and pathologic characteristics}

\begin{tabular}{|c|c|c|c|}
\hline Characteristics & & $n$ & $\%$ \\
\hline & IA & 272 & 64.3 \\
\hline & IB & 52 & 12.3 \\
\hline & $\|$ & 7 & 1.7 \\
\hline & IIIA & 11 & 2.6 \\
\hline 2009 FIGO stage & IIIB & - & - \\
\hline & IIIC1 & 21 & 5 \\
\hline & IIIC2 & 29 & 6.9 \\
\hline & IVA & 5 & 1.2 \\
\hline & IVB & 26 & 6.1 \\
\hline & 1 & 230 & 54.4 \\
\hline & 2 & 120 & 28.4 \\
\hline & 3 & 68 & 16.1 \\
\hline & Not reported & 2 & 1.2 \\
\hline & No invasion & 54 & 12.8 \\
\hline & $<1 / 2$ & 240 & 56.7 \\
\hline invasion & $\geq 1 / 21$ & 110 & 26 \\
\hline & Uterine serosal invasion & 13 & 3.1 \\
\hline & Not reported & 6 & 1.4 \\
\hline & Negative & 365 & 86.3 \\
\hline & Glandular & 15 & 3.5 \\
\hline 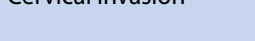 & Stromal & 37 & 8.7 \\
\hline & Not reported & 6 & 1.4 \\
\hline & Negative & 276 & 65.2 \\
\hline $\begin{array}{l}\text { Lymphovascular space } \\
\text { invasion }\end{array}$ & Positive & 108 & 25.5 \\
\hline & Not reported & 39 & 9.2 \\
\hline & Negative & 388 & 91.7 \\
\hline Peritoneal cytology & Positive & 21 & 5 \\
\hline & Not reported & 14 & 3.3 \\
\hline & Negative & 385 & 91 \\
\hline Adnexal metastasis & Positive & 33 & 7.8 \\
\hline & Not reported & 5 & 1.2 \\
\hline & Negative & 379 & 89.6 \\
\hline Omental metastasis & Positive & 21 & 5 \\
\hline & Not reported & 23 & 5.4 \\
\hline $1+2$ & Negative & 186 & 75.6 \\
\hline & Positive & 60 & 24.4 \\
\hline
\end{tabular}

1 - except for uterine serosal invasion; 2 - lymphadenectomy performed to 246 patients

lympho-vascular space invasion (LVSI), cervical invasion, omental metastasis, large tumor size, and LNM (Tab. 2). The mean CA125 level in patients with stage IA was $22.2 \mathrm{IU} / \mathrm{mL}$. Although higher CA125 levels are associated with advanced stage, among the patients with stage IA disease, CA125 level was $>100 \mathrm{IU} / \mathrm{mL}$ in $2.2 \%$, $>50 \mathrm{IU} / \mathrm{mL}$ in $10 \%$, and $>35 \mathrm{IU} / \mathrm{mL}$ in $14 \%$ patients. The lymphatic involvement site was not related with CA125 level (stage IIIC1 vs. IIIC2: $56.4 \mathrm{IU} / \mathrm{mL}$ vs. $77.9 \mathrm{IU} / \mathrm{mL}$, respectively; $p=0.454$ ).

In the entire study group, high CA125 level (> 35) significantly predicted advanced stage of disease, deep myometrial invasion, LVSI, uterine serosal involvement, cervical invasion, adnexal involvement, positive peritoneal cytology, omental metastasis, and LNM (Tab. 3). The likelihood of LNM increased from $15.9 \%$ to $45.7 \%$ if the CA125 level was > $35 \mathrm{IU} / \mathrm{mL}$.

The CA125 level that predicted surgical prognostic factors changed with age. The predictive value of the conventional cut-off level for surgical prognostic factors in patients aged $>50$ years was similar to that for the whole group, while CA125 level did not predict omental and LNM in patients aged $\leq 50$ years (Tab. 3). LNM was predicted in $15 \%$ of older patients ( $>50$ years) with a CA125 level of $\leq 35 \mathrm{IU} / \mathrm{mL}$, whereas it was determined in $48 \%$ of the older patients with CA125 level $>35 \mathrm{IU} / \mathrm{mL}(\mathrm{p}<0.0001)$. In contrast, in younger patients, LNM prediction rates were $21 \%$ and $40 \%$, respectively $(p=0.124)$.

In younger patients ( $\leq 50$ years) who underwent lymphadenectomy, the data on preoperative CA125 levels were insufficient to define the cut-off values, and the discriminatory power for LNM was low; the area under the curve value was 0.656 (95\% confidence interval: $0.481-0.831 ; p=0.077$ ) (Fig. 1). However, in older patients ( $>50$ years) with lymphadenectomy, preoperative CA125 level was predictable for LNM and area under the curve value was 0.695 (95\% confidence interval: 0.602-0.787; $p<0.0001$ ) (Fig. 2). In this group, the optimal preoperative CA125 cut-off value for predicting LNM was $16 \mathrm{IU} / \mathrm{mL}$. In $43 \%$ of the patients aged $>50$ years, CA125 level was $>16 \mathrm{IU} / \mathrm{mL}$. LNM was observed in $13 \%$ and $35 \%$ of the patients with a CA125 level of $\leq 16 \mathrm{IU} / \mathrm{mL}$ and $>16 \mathrm{IU} / \mathrm{mL}$, respectively $(p<0.0001)$. The sensitivity, specificity, positive predictive value (PPV), and negative predictive value (NPV) of this level for LNM prediction were $71 \%, 60 \%, 35 \%$, and $87 \%$, respectively.

Sixteen patients were not included in the recurrence analysis because of lost to follow-up after undergoing initial surgery. The median follow-up period of 407 patients was 44 months (range: 1-240 months). In this period, recurrence was detected in 49 patients (11.6\%). In the whole group, the median CA125 level in patients who experienced a recurrence was higher than that in patients who did not experience recurrence (respectively, $92.1 \mathrm{IU} / \mathrm{mL}$ vs. $34 \mathrm{IU} / \mathrm{mL}$; $\mathrm{p}<0.0001)$. The conventional cut-off level predicted recurrence. Recurrence developed in $22.8 \%$ and $8.9 \%$ of the patients with CA125 levels of $\geq 35 \mathrm{IU} / \mathrm{mL}$ and $<35 \mathrm{IU} / \mathrm{mL}$, respectively $(p<0.0001)$. However, this association was not observed in the patients with earlier stage of the disease. In the patients with FIGO stage I and II disease, recurrence developed in $9.4 \%$ and $4.5 \%$ of the patients with CA125 levels of $\geq 35 \mathrm{IU} / \mathrm{mL}$ and $<35 \mathrm{IU} / \mathrm{mL}$, respectively $(p=0.139)$. None of the patients with FIGO stage IA dis- 
Table 2. Associations between preoperative CA125 level and clinical, surgical, pathologic features in endometrioid type endometrial cancer

\begin{tabular}{|c|c|c|c|c|}
\hline \multicolumn{2}{|l|}{ Factors } & \multirow{2}{*}{\begin{tabular}{|l|} 
Mean \\
41.3
\end{tabular}} & \multirow{2}{*}{$\begin{array}{l}\text { Median (Range) } \\
14(1-500)\end{array}$} & \multirow{3}{*}{$\begin{array}{l}\text { p value } \\
0.676\end{array}$} \\
\hline \multirow{2}{*}{ Age } & $\leq 57$ years & & & \\
\hline & $\geq 58$ years & 40.9 & $13.5(1-1461)$ & \\
\hline \multirow{8}{*}{2009 FIGO stage } & IA & 22.2 & $13(1-348)$ & \multirow{8}{*}{$<0.0001$} \\
\hline & IB & 33.7 & $13(1-289)$ & \\
\hline & $\|$ & 119 & $46(8-391)$ & \\
\hline & IIIA & 65.9 & $24(3-500)$ & \\
\hline & IIIC1 & 56.4 & $23(1-473)$ & \\
\hline & IIIC2 & 77.9 & $29(1-365)$ & \\
\hline & IVA & 52.4 & $12(1-195)$ & \\
\hline & IVB & 153.9 & $37(1-1461)$ & \\
\hline \multirow{3}{*}{ FIGO grade } & Grade 1 & 30.6 & $13(1-500)$ & \multirow{3}{*}{0.031} \\
\hline & Grade 2 & 44.2 & $18.5(1-500)$ & \\
\hline & Grade 3 & 66.8 & $13.5(1-1461)$ & \\
\hline \multirow{3}{*}{ Depth of myometrial invasion } & No invasion & 29.4 & $13.5(1-348)$ & \multirow{3}{*}{$<0.0001$} \\
\hline & $<1 / 2$ & 23.8 & $13(1-391)$ & \\
\hline & $\geq 1 / 21$ & 58.1 & $20(1-500)$ & \\
\hline \multirow{2}{*}{ Uterine serosal invasion } & Negative & 33.8 & $14(1-500)$ & \multirow{2}{*}{$<0.0001$} \\
\hline & Positive & 252 & $48(1-1461)$ & \\
\hline \multirow{2}{*}{ Lympho-vascular space invasion } & Negative & 24 & $13(1-348)$ & \multirow{2}{*}{$<0.0001$} \\
\hline & Positive & 76.5 & $20(1-1461)$ & \\
\hline \multirow{3}{*}{ Cervical invasion } & Negative & 29.9 & $13(1-500)$ & \multirow{3}{*}{$<0.0001$} \\
\hline & Glandular & 47.6 & $23(2-339)$ & \\
\hline & Stromal & 140.3 & $39(1-1461)$ & \\
\hline \multirow{2}{*}{ Adnexal metastasis } & Negative & 29.6 & $13(1-391)$ & \multirow{2}{*}{$<0.0001$} \\
\hline & Positive & 169.5 & $37(3-1461)$ & \\
\hline \multirow{2}{*}{ Peritoneal cytology } & Negative & 30.3 & $13.5(1-473)$ & \multirow{2}{*}{$<0.0001$} \\
\hline & Positive & 178.1 & $37(3-1461)$ & \\
\hline \multirow{2}{*}{ Omental metastasis } & Negative & 32.7 & $14(1-500)$ & \multirow{2}{*}{$<0.0001$} \\
\hline & Positive & 191.9 & $37(1-1461)$ & \\
\hline \multirow{2}{*}{ Tumor size } & $\leq 40 \mathrm{~mm}$ & 24.3 & $11(1-289)$ & \multirow{2}{*}{0.002} \\
\hline & $\geq 41 \mathrm{~mm}$ & 91.4 & $27(1-1461)$ & \\
\hline \multirow{2}{*}{ Lymph node metastasis2 } & Negative & 40.3 & $14(1-1461)$ & \multirow{2}{*}{0.011} \\
\hline & Positive & 87.2 & $37(1-500)$ & \\
\hline
\end{tabular}

1 - except for uterine serosal invasion; $2-n=246$ patients underwent lymphadenectomy; $p<0.05$ is statistically significant

ease and whose CA125 level was $\geq 100 \mathrm{lU} / \mathrm{mL}$ had disease recurrence. Five-year DFS of the entire cohort was $85 \%$. In univariate analysis, preoperative CA125 level, disease stage, and all pathologic features were significantly associated with DFS (Tab. 4). In multivariate analysis, both grade and conventional CA125 level were independent prognostic factors for the risk of recurrence $(p=0.000)$ (Tab. 5).

\section{DISCUSSION}

LNM is one of the most important prognostic factors for EC; therefore, the prediction of LNM preoperatively has a critical significance in the treatment plan [12]. Preoperative CA125 level is useful as a reliable tumor marker in the management of EC $[3,6,13,14]$.

Most studies revealed that CA125 is an independent predictor of extra-uterine spread in EC [13, 15-17]. There were differences in the correlations between high CA125 levels and clinical-pathological findings. Chao et al. and Jiang et al. determined that high CA125 levels among the patients with EC strongly correlated with advanced stage of disease, moderate to poor differentiation, deep myometrial invasion, LVSI, positive peritoneal cytology, and LNM, but they 


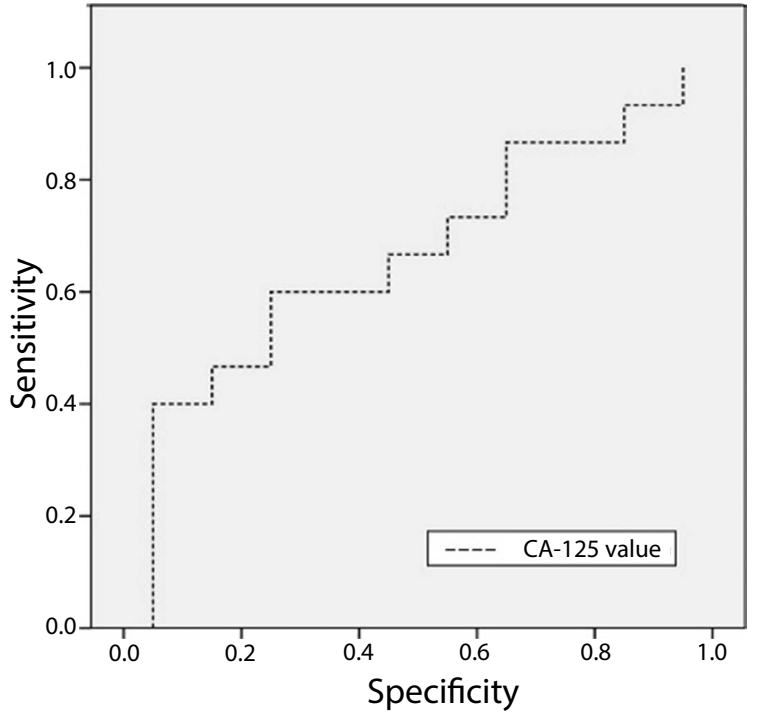

Figure 1. In younger patients ( $\leq 50$ years), the discriminatory power of receiver operating characteristic analysis was low for predicting lymph node metastases

did not find any association between CA125 level and the type of histology $[4,5]$. Dotters et al. found that elevated CA125 levels were associated with LVSI and positive peritoneal cytology but not with nodal metastases [18]. Kim et al. and Chung et al. did not find any statistically significant association between grade and higher CA125 levels $[6,8]$. Furthermore, addition of preoperative CA125 levels to models including imaging techniques or pathologic features significantly increases the rates of LNM prediction [14, 19].

In our study, the mean CA125 level in endometrioid-type EC was significantly lower than that in non-endometrioid-type EC. Moreover, CA125 level of $>35 \mathrm{IU} / \mathrm{mL}$ was significantly associated with all of the studied poor prognostic factors, except grade. This relationship was elucidated based on the following two observations: (1) immunohistochemical staining revealed that solid and undifferentiated areas of EC have low levels of CA125 positivity, therefore high-grade tumors may express CA125 less strongly than well-differentiated tumors; (2) serum CA125 level is related to intraperitoneal dissemination of cancer cells or dissemination via the lympho-vascular system or is associated with bulky nodal metastases $[18,20]$.

The optimal cut-off levels of CA125 still remain controversial. The best cut-off levels for the prediction of poor prognostic factors ranged from 16.2 to $65 \mathrm{IU} / \mathrm{mL}[6-8,16]$. Hsieh et al. showed that the risk of high CA125 level (> $35 \mathrm{IU} / \mathrm{mL}$ ) was 7.7 fold higher in patients with positive nodal metastases [7]. In our study, LNM probability increased from $15.9 \%$ to $45.7 \%$ when CA125 level was > $35 \mathrm{lU} / \mathrm{mL}$. However, we did not find any significant association between CA125 level and localization of metastatic lymph node (pelvic or paraaortic).

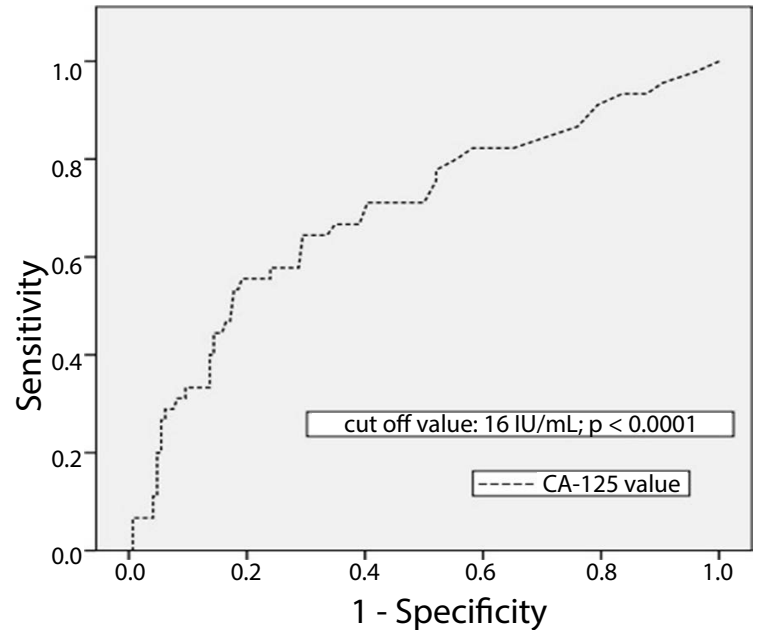

Figure 2. The best cut-off value of preoperative CA125 in older patients ( $>50$ years) that predicted lymph node metastases

The best cut-off values for predicting LNM ranged from 15 to $50 \mathrm{IU} / \mathrm{mL}[6-9,16,18,21-23]$. Koper et al. found that while the sensitivity of a cut-off value of $15 \mathrm{IU} / \mathrm{mL}$ was higher than the conventional cut-off value $(35 \mathrm{IU} / \mathrm{mL})$ for identifying patients who would have required a lymphadenectomy ( $53 \%$ vs. $17 \%$, respectively), the specificity of this cut-off level was lower than that of the conventional cut-off level ( $76 \%$ vs. $95 \%$, respectively) [22]. Choi et al. demonstrated that the best CA125 cut-off level was $50 \mathrm{IU} / \mathrm{mL}$, with a sensitivity of $80 \%$ and a specificity of $73 \%$ for LNM [21].

The conventional cut-offCA 125 level could predict LNM in older patients, but this association was not found in younger patients in the present study. Therefore, age-stratified cut-off level is important to predict the prognostic factors accurately. Yıldız et al. determined that $20 \mathrm{IU} / \mathrm{mL}$ cut-off value in the postmenopausal period was more appropriate to detect LNM, and the sensitivity, specificity, PPV, and NPV of this value for LNM prediction were $75 \%, 69.5 \%, 80.6 \%$, and $84.9 \%$, respectively [23]. In a study conducted by Han et al., the cut-off CA125 level for predicting $L N M$ in patients aged $>50$ years ( $\geq 28 \mathrm{IU} / \mathrm{mL}$ ) was higher than that in younger patients ( $\geq 20 \mathrm{IU} / \mathrm{mL}$ ) [9]. Despite this observation, Chao et al. demonstrated that in young patients, the cut-off value was higher and they attributed this result to other conditions that caused an increase in the CA125level, such as menstruation, endometriosis, and fibroids, which were more likely to be noted in young patients [4]. In our study, the optimal cut-off value was determined to be $16 \mathrm{IU} / \mathrm{mL}$ for patients aged > 50 years. The sensitivity, specificity, PPV, and NPV of this level for predicting LNM in these patients were $71 \%, 60 \%, 35 \%$, and $87 \%$, respectively; however, the optimal cut-off value could not be determined among patients aged $<50$ years.

Imaging techniques, such as ultrasonography or magnetic resonance imaging, have a limited value to 
Table 3. Relation between preoperative CA125 level and surgical-pathologic factors in the entire cohort and in groups stratified by age

\begin{tabular}{|c|c|c|c|c|c|c|c|c|c|}
\hline \multirow{3}{*}{ Factors (\% patients) } & \multirow[t]{2}{*}{ CA 125 level } & & & \multicolumn{3}{|c|}{ Age $\leq \mathbf{5 0}$ years } & \multicolumn{3}{|c|}{ Age $>50$ years } \\
\hline & & \multicolumn{3}{|l|}{ CA 125 level } & \multicolumn{3}{|l|}{ CA 125 level } & & \multirow[b]{2}{*}{ p value } \\
\hline & $\leq 35 \mathrm{IU} / \mathrm{mL}$ & $>35 \mathrm{IU} / \mathrm{mL}$ & p value & $\leq 35 \mathrm{IU} / \mathrm{mL}$ & $>35 \mathrm{IU} / \mathrm{mL}$ & p value & $\leq 35 \mathrm{IU} / \mathrm{mL}$ & $>35 \mathrm{IU} / \mathrm{mL}$ & \\
\hline \multicolumn{10}{|l|}{ FIGO stage } \\
\hline |\&11 & 84.5 & 56.8 & \multirow{2}{*}{$<0.0001$} & 78.6 & 53.8 & \multirow{2}{*}{0.017} & 85.4 & 56.7 & \multirow{2}{*}{$<0.0001$} \\
\hline III\&IV & 15.5 & 43.2 & & 21.4 & 46.2 & & 14.6 & 42.3 & \\
\hline \multicolumn{10}{|l|}{ FIGO grade } \\
\hline Grade 1 & 57.4 & 46.8 & \multirow{3}{*}{0.191} & 58 & 44 & \multirow{3}{*}{0.461} & 56 & 46.3 & \multirow{3}{*}{0.359} \\
\hline Grade 2 & 27.2 & 34 & & 29 & 36 & & 27.1 & 34.3 & \\
\hline Grade 3 & 15.4 & 19.2 & & 13 & 20 & & 16.9 & 19.4 & \\
\hline \multicolumn{10}{|c|}{ Depth of myometrial invasion } \\
\hline No invasion & 14.2 & 10.3 & \multirow{3}{*}{0.001} & 17.9 & 4.3 & \multirow{3}{*}{0.018} & 13.4 & 11.3 & \multirow{3}{*}{0.011} \\
\hline$<1 / 2$ & 63.1 & 46 & & 65.7 & 52.2 & & 60.9 & 43.5 & \\
\hline$\geq 1 / 21$ & 22.7 & 43.7 & & 16.4 & 43.5 & & 25.6 & 45.2 & \\
\hline \multicolumn{10}{|l|}{ Uterine serosal invasion } \\
\hline Negative & 98.1 & 92.6 & \multirow{2}{*}{0.006} & 98.5 & 88.5 & \multirow{2}{*}{0.031} & 98 & 93.9 & \multirow{2}{*}{0.085} \\
\hline Positive & 1.9 & 7.4 & & 1.5 & 11.5 & & 2 & 6.1 & \\
\hline \multicolumn{10}{|c|}{ Lympho-vascular space invasion } \\
\hline Negative & 77.4 & 51.8 & \multirow{2}{*}{$<0.0001$} & 82.3 & 52.2 & \multirow{2}{*}{0.005} & 74.9 & 50 & 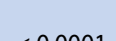 \\
\hline Positive & 22.6 & 48.2 & & 17.7 & 47.8 & & 25.1 & 50 & $<0.0001$ \\
\hline Cervical invasion & & & & & & & & & \\
\hline Negative & 92 & 72 & & 88.2 & 61.5 & & 92.6 & 75.4 & \\
\hline Glandular & 2.8 & 6.5 & $<0.0001$ & 5.9 & - & $<0.0001$ & 2 & 9.2 & $<0.0001$ \\
\hline Stromal & 5.2 & 21.5 & & 5.9 & 38.5 & & 5.3 & 15.4 & \\
\hline Adnexal metastasis & & & & & & & & & \\
\hline Negative & 95.1 & 81.9 & 1000001 & 91.8 & 69.2 & pon & 95.9 & 86.4 & \\
\hline Positive & 4.9 & 18.1 & $<0.0001$ & 8.8 & 30.8 & 0.000 & 4.1 & 13.6 & 0.004 \\
\hline Peritoneal cytology & & & & & & & & & \\
\hline Negative & 96.9 & 87.6 & & 96.9 & 84 & & 96.7 & 88.7 & \\
\hline Positive & 3.1 & 12.4 & $<0.0001$ & 3.1 & 16 & $0.0<0$ & 3.3 & 11.3 & 0.009 \\
\hline Omental metastasis & & & & & & & & & \\
\hline Negative & 97.1 & 86.5 & & 95.3 & 83.3 & & 97.4 & 87.3 & \\
\hline Positive & 2.9 & 14.5 & $<0.0001$ & 4.7 & 16.7 & 0.004 & 2.6 & 12.7 & 0.001 \\
\hline Lymph node metastas & & & & & & & & & \\
\hline Negative & 84.1 & 54.3 & & 79 & 60 & 0124 & 85 & 52 & \\
\hline Positive & 15.9 & 45.7 & $<0.0001$ & 21 & 40 & 0.124 & 15 & 48 & $<0.0001$ \\
\hline
\end{tabular}

1 - uterine serosal invasion excluded; $2-n=246$ patients underwent lymphadenectomy, $\mathrm{p}<0.05$ is statistically significant

determine recurrence in small lesions or to evaluate the probability of recurrent disease, but CA125 levels are considered to be important in this regard. Nikolaou et al. found that the mean preoperative CA125 level of patients with recurrence was higher than that of patients without recurrence, but the difference was not statistically significant (49.4 IU/mL vs. $29.5 \mathrm{IU} / \mathrm{mL} ; \mathrm{p}=0.242$ ) [24]. On the contrary, in our study, the patients with recurrence had a sig- nificantly higher preoperative CA125 level than patients without recurrence (respectively, $92.1 \mathrm{IU} / \mathrm{mL}$ vs. $34 \mathrm{IU} / \mathrm{mL}$; $\mathrm{p}<0.0001)$. Additionally, preoperative CA125 level independently predicted the development of recurrence. The recurrence probability increased by approximately three fold when the CA125 level was higher than the conventional cut-off level (respectively, $22.8 \%$ vs. $8.9 \%$; $\mathrm{p}<0.0001)$. 


\begin{tabular}{|c|c|c|c|}
\hline & & \multicolumn{2}{|c|}{ Disease Free Survival } \\
\hline & & 5-year [\%] & p value \\
\hline \multirow{2}{*}{ Age } & $\leq 50$ & 86 & \multirow{2}{*}{0.732} \\
\hline & $50<$ & 84 & \\
\hline \multirow{2}{*}{ Preoperative CA 125 level (IU/mL) } & $\leq 35$ & 88 & \multirow{2}{*}{$0.000^{*}$} \\
\hline & $35<$ & 72 & \\
\hline \multirow{2}{*}{ Stage } & $|\&| \mid$ & 93 & \multirow{2}{*}{$0.000^{*}$} \\
\hline & III\&IV & 55 & \\
\hline \multirow{3}{*}{ Grade } & 1 & 90 & \multirow{3}{*}{$0.000^{*}$} \\
\hline & 2 & 83 & \\
\hline & 3 & 69 & \\
\hline \multirow{3}{*}{ Depth of myometrial invasion } & No invasion & 100 & \multirow{3}{*}{$0.000^{*}$} \\
\hline & $<1 / 2$ & 92 & \\
\hline & $\geq 1 / 21$ & 67 & \\
\hline \multirow{2}{*}{ Serosal involvement } & Negative & 86 & \multirow[t]{2}{*}{$0.000^{*}$} \\
\hline & Positive & 38 & \\
\hline \multirow{2}{*}{ Lympho-vascular space invasion } & Negative & 93 & \multirow[t]{2}{*}{$0.000^{*}$} \\
\hline & Positive & 71 & \\
\hline \multirow{3}{*}{ Cervical invasion } & Negative & 87 & \multirow{3}{*}{$0.000^{*}$} \\
\hline & Glandular & 90 & \\
\hline & Stromal & 57 & \\
\hline \multirow{2}{*}{ Adnexal metastasis } & Negative & 89 & \multirow[t]{2}{*}{$0.000^{*}$} \\
\hline & Positive & 41 & \\
\hline \multirow{2}{*}{ Peritoneal cytology } & Negative & 88 & \multirow[t]{2}{*}{$0.000^{*}$} \\
\hline & Positive & 31 & \\
\hline \multirow{2}{*}{ Omental metastasis } & Negative & 87 & \multirow[t]{2}{*}{$0.000^{*}$} \\
\hline & Positive & 24 & \\
\hline \multirow{2}{*}{ Lymph node metastasis2 } & Negative & 85 & \multirow[t]{2}{*}{$0.000^{*}$} \\
\hline & Positive & 56 & \\
\hline
\end{tabular}

1 - uterine serosal invasion excluded; $2-n=246$ patients underwent lymphadenectomy; ${ }^{*} \mathrm{p}<0.05$ is statistically significant

Table 5. Multi-variant analysis for prediction of recurrence

\begin{tabular}{|l|l|l|}
\hline & Hazard Ratio $(\mathbf{9 5} \% \mathrm{Cl})$ & p value \\
\hline Factors & \multicolumn{2}{l}{} \\
\hline CA 125 level $(\leq 35 \mathrm{IU} / \mathrm{mL}$ vs. $35 \mathrm{IU} / \mathrm{mL}<)$ & $3.03(1.7-5.3)$ & $0.000^{*}$ \\
\hline Grade (I\&II vs. III) & $3.00(1.6-5.4)$ & $0.000^{*}$ \\
\hline
\end{tabular}

${ }^{*} \mathrm{p}<0.05$ is statistically significant

One of the limitations of this study was its retrospective design. Another limitation is that the elevation in other tumor marker levels was not evaluated. Nevertheless, this is one of the large-scale studies evaluating the preoperative CA125 cut-off level for the prediction of LNM and other prognostic factors in endometrioid-type EC.

\section{CONCLUSIONS}

The preoperative conventional cut-off level of CA125 is a useful marker to predict the poor surgical prognostic factors and risk of recurrence. More importantly, the age-dependent cut-off value of CA125 must be taken into consideration because such cut-off values can improve the 
prediction of LNM in endometrioid-type EC. The optimal cut-off value that can predict LNM in older patients was determined to be $16 \mathrm{IU} / \mathrm{mL}$ in our study. Preoperative conventional or age-dependent cut-off value of CA125 in EC should be considered to refer the patient to a gynecological oncology clinic preoperatively. Consequently, the risk of second surgery can be decreased. However, further studies are needed to evaluate the optimum cut-off level of CA125 in younger patients.

\section{Conflict of interest}

The authors declare no competing interest. No financial support was received for this study.

\section{REFERENCES}

1. Siegel R, Miller K, Jemal A. Cancer statistics, 2015. CA: A Cancer Journal for Clinicians. 2015; 65(1): 5-29, doi: 10.3322/caac.21254.

2. Morice $P$, Leary $A$, Creutzberg $C$, et al. Endometrial cancer. The Lancet. 2016; 387(10023): 1094-1108, doi: 10.1016/s0140-6736(15)00130-0.

3. Burke W, Orr J, Leitao M, et al. Endometrial cancer: A review and current management strategies: Part I. Gynecologic Oncology. 2014; 134(2): 385-392, doi: 10.1016/j.ygyno.2014.05.018.

4. Chao A, Tang YH, Lai CH, et al. Potential of an age-stratified CA125 cut-off value to improve the prognostic classification of patients with endometrial cancer. Gynecologic Oncology. 2013; 129(3): 500-504, doi: 10.1016/j.ygyno.2013.02.032.

5. Jiang T, Huang L, Zhang S. Preoperative serum CA125: a useful marker for surgical management of endometrial cancer. BMC Cancer. 2015; 15 : 396, doi: 10.1186/s12885-015-1260-7, indexed in Pubmed: 25964114.

6. Chung HH, Kim JW, Park NH, et al. Use of preoperative serum CA-125 levels for prediction of lymph node metastasis and prognosis in endometrial cancer. Acta Obstetricia et Gynecologica Scandinavica. 2006; 85(12): 1501-1505, doi: 10.1080/00016340601022777.

7. Hsieh $\mathrm{CH}$, ChangChien CC, $\mathrm{Lin} \mathrm{H}$, et al. Can a preoperative $\mathrm{CA} 125$ level be a criterion for full pelvic lymphadenectomy in surgical staging of endometrial cancer? Gynecol Oncol. 2002; 86(1): 28-33, indexed in Pubmed: 12079296.

8. Kim H, Park CY, Lee JM, et al. Evaluation of serum CA-125 levels for preoperative counseling in endometrioid endometrial cancer: A multi-center study. Gynecologic Oncology. 2010; 118(3): 283-288, doi: 10.1016/j. ygyno.2010.04.018.

9. Han SS, Lee $S$, Kim D, et al. Evaluation of preoperative criteria used to predict lymph node metastasis in endometrial cancer. Acta Obstetricia et Gynecologica Scandinavica. 2010; 89(2): 168-174, doi: 10.3109/00016340903370114.
10. Pecorelli S. Revised FIGO staging for carcinoma of the vulva, cervix, and endometrium. Int J Gynaecol Obstet. 2009; 105(2): 103-104, indexed in Pubmed: 19367689.

11. Studies HUloP. 2013 Turkey Demographic and Health Survey. Hacettepe University Institute of Population Studies,TR Ministry of Development and TÜBITAK, Ankara, Turkey. 2014.

12. Turan T, Ureyen I, Duzguner I, et al. Analysis of Patients With Stage IIIC Endometrial Cancer. International Journal of Gynecological Cancer. 2014; 24(6): 1033-1041, doi: 10.1097/igc.0000000000000154.

13. Powell JL, Hill KA, Shiro BC, et al. Preoperative serum CA-125 levels in treating endometrial cancer. J Reprod Med. 2005; 50(8): 585-590, indexed in Pubmed: 16220763.

14. Yang B, Shan B, Xue X, et al. Predicting Lymph Node Metastasis in Endometrial Cancer Using Serum CA125 Combined with Immunohistochemical Markers PR and Ki67, and a Comparison with Other Prediction Models. PLOS ONE. 2016; 11(5): e0155145, doi: 10.1371/journal. pone.0155145.

15. Nicklin J, Janda M, Gebski V, et al. The utility of serum CA-125 in predicting extra-uterine disease in apparent early-stage endometrial cancer. International Journal of Cancer. 2011; 131(4): 885-890, doi: 10.1002/ijc.26433.

16. Sood AK, Buller RE, Burger RA, et al. Value of preoperative CA 125 level in the management of uterine cancer and prediction of clinical outcome. Obstet Gynecol. 1997; 90(3): 441-447, indexed in Pubmed: 9277659.

17. Schmidt M, Segev Y, Sadeh R, et al. Cancer Antigen 125 Levels are Significantly Associated With Prognostic Parameters in Uterine Papillary Serous Carcinoma. International Journal of Gynecological Cancer. 2018; 28(7): 1311-1317, doi: 10.1097/igc.0000000000001300.

18. Dotters D. Preoperative CA 125 in endometrial cancer: Is it useful? American Journal of Obstetrics and Gynecology. 2000; 182(6): 1328-1334, doi: 10.1067/mob.2000.106251.

19. Kang S, Nam JH, Bae DS, et al. Preoperative assessment of lymph node metastasis in endometrial cancer: A Korean Gynecologic Oncology Group study. Cancer. 2016; 123(2): 263-272, doi: 10.1002/cncr.30349.

20. Ginath S, Menczer J, Fintsi Y, et al. Tissue and serum CA125 expression in endometrial cancer. Int J Gynecol Cancer. 2002; 12(4): 372-375, indexed in Pubmed: 12144685.

21. Choi YS, Koh SB, Ahn JY, et al. Usefulness of preoperative CA125 leve in decision making of lymphadenectomy in endometrial cancer patients. Korean J Obstet Gynecol. 2005; 48: 2877-87.

22. Koper NP, Massuger LF, Thomas CM, et al. Serum CA 125 measurements to identify patients with endometrial cancer who require lymphadenectomy. Anticancer Res. 1998; 18(3B): 1897-1902, indexed in Pubmed: 9677441

23. Yildiz A, Yetimalar H, Kasap B, et al. Preoperative serum CA 125 level in the prediction of the stage of disease in endometrial carcinoma. European Journal of Obstetrics \& Gynecology and Reproductive Biology. 2012; 164(2): 191-195, doi: 10.1016/j.ejogrb.2012.05.038.

24. Nikolaou M, Kourea HP, Tzelepi V, et al. The prognostic role of preoperative serum CA 125 levels in patients with endometrial carcinoma. J BUON. 2014; 19(1): 198-202, indexed in Pubmed: 24659664. 